\title{
Algumas considerações sobre o lugar da filosofia nietzschiana em $O$ homem sem qualidades de Robert Musil
}

\author{
Silvia Bento*
}

\begin{abstract}
Resumo: O presente artigo propõe desenvolver uma análise da influência da filosofia de Nietzsche no âmbito da obra literária de Robert Musil, especialmente em $O$ homem sem qualidadades (Der Mann ohne Eigenshcaften). É nosso propósito compreender a relevância da filosofia nietzschiana no âmbito da maturidade de Musil, refutando, assim, a conclusão avançada por Jacques Bouveresse relativamente à filosofia nietzschiana como uma mera (e infecunda) paixão de juventude do escritor austríaco. Neste sentido, a análise da importância da vivissecção, enquanto tarefa filosófico-psicológica proclamada por Nietzsche (em Além do bem e do mal) no âmbito do romance de Musil - Musil enquanto vivisecteur e psicólogo - forma o núcleo deste artigo.
\end{abstract}

Palavras-chave: Robert Musil, Nietzsche, vivissecção, psicologia.

\footnotetext{
*Universidade do Porto, Porto, Portugal.

ORCID https://orcid.org/0000-0001-6893-5513

Correio eletrônico: silviaandradebento@gmail.com
} 
Bento, S.

\section{Introdução. Musil, filósofo entre filósofos}

A proclamação de Robert Musil como eminente filósofo, tal como desenvolvida por Jacques Bouveresse ${ }^{1}$, integra a análise do pensamento do escritor como um eixo relevante da designada "filosofia austríaca". Neste sentido, segundo Bouveresse, um dos mais assertivos estudiosos da filosofia de Musil, a interpretação do pensamento do escritor exigiria a consideração da emergência da denominada filosofia austríaca das primeiras décadas do século XX, essencialmente representada pela epistemologia de Ernst Mach, o designado empirocriticismo, e pela filosofia, de pendor lógico e antimetafísico do Círculo de Viena. Tal como Bouveresse propõe, a obra de Musil poderia ser perspetivada à luz da sua intenção artística de transposição da postura de exatidão/ precisão filosóficas e de avaliação da ausência de substancialidade metafísica da realidade para o domínio da literatura e do estudo dos estados psicológicos das personagens. A obra literária de Musil, assim apreciada, formaria uma peça-chave da filosofia austríaca, concebida na sua atitude de refutação dos conceitos centrais da metafísica tradicional: com efeito, a ênfase na diferenciação da filosofia austríaca (com as suas formulações sobre a predominância da lógica e da psicologia sobre a metafísica) relativamente à filosofia alemã (com a sua tonalidade místico-metafísica, de Meister Eckhart a Heidegger) constitui um aspeto substancial da interpretação de Musil por Bouveresse.

A inserção de Musil, o filósofo, no domínio da filosofia analítica - tarefa empreendida por Bouveresse, que, com efeito, procurou, mais do que ninguém, apresentar o pensamento e a obra musilianos como um dos "cavalos de batalha" da contenda analítica vs. continental assistiu a repercussões recentes (e não menos apreciáveis): referimonos ao número especial, de 2014, inteiramente dedicado a Musil, da revista The Monist $^{2}$, editado por Bence Nanay e com contribuições

1 Ver Bouveresse, 1993, 2001.

2 Ver The Monist, Vol.97, N.1, January 2014.

176 | Cad. Nietzsche, Guarulhos/Porto Seguro, v.42, n.2, p. 175-199, maio/agosto, 2021. 
Algumas considerações sobre o lugar da filosofia nietzschiana em...

de, entre outros, Kevin Mulligan. Poder-se-ia, no seguimento de tais considerações, sustentar: Musil, assim lido e perspetivado, apresentar-se-ia, pois, como o filósofo perdido, doravante recuperado e reconhecido, da grande tradição da filosofia analítica austríaca.

Não obstante a pertinência da leitura de Bouveresse, apostada em apresentar a dimensão eminentemente filosófica do pensamento do escritor austríaco, importaria sublinhar, aí, a ausência de uma análise aprofundada das relações da obra de Musil com o pensamento de Nietzsche, inequivocamente o filósofo mais repetidamente mencionado ao longo da æeuvre musiliana. A convicção de que a influência de Nietzsche no âmbito do pensamento e da obra de Musil se reduz a uma intelectual paixão de juventude deste último, tal como sustenta Bouveresse, não permite, assim cremos, o desenvolvimento de uma perspetivação passível de avaliar toda a dimensão do diálogo que Musil mantém com a filosofia nietzschiana - e, acrescentar-se-ia, com o vulto cultural de Nietzsche. Impor-se-á, assim, a premência de um alargamento do âmbito da análise para lá da questão da paixão juvenil. A convocação de Nietzsche - pensamento, obra e vulto cultural - é assaz recorrente (dir-se-ia ininterrupta) ao longo da œuvre musiliana, e a sua complexidade não deverá ser descurada pelo leitor filosoficamente mais avisado.

\section{Nietzsche-Spuren no âmbito de $O$ homem sem qualidades. Uma primeira leitura}

Permitamo-nos começar evocando a personagem musiliana que concentra e propaga, ao longo de $O$ homem sem qualidades (Der Mann ohne Eigenschaften), os vestígios, certamente explícitos e incisivamente proclamatórios, do pensamento de Nietzsche. Trata-se da personagem Clarisse, amiga próxima de Ulrich e mulher de Walter. Tal como sublinha Nesrin Taskiran no ensaio com o ilustrativo título Wahnsinn hat Methode. Zur Clarisse-Figur und weiteren Nietzsche- 
Bento, S.

Spuren in Musil's "Mann ohne Eigenschaften"3, o trio Ulrich-ClarisseWalter apresenta-se como um dos eixos estruturantes do romance, particularmente se atentarmos sobre a oposição entre as figuras Ulrich, o (novo) homem sem qualidades, e Walter, o gênio musical decadente e frustradamente romântico. $\mathrm{O}$ abismo cultural que se abre entre estas duas figuras, como que agonicamente arquetípicas, deverá ser aqui apontado. A inserção da personagem feminina, Clarisse umas das poucas personagens femininas, juntamente com Agathe, cuja eroticidade latente nunca constitui alvo de sardônico desprezo por parte de Ulrich -, afigura-se como a evocação ficcionada do pensamento de Nietzsche, especialmente no que concerne à crítica cultural. Estamos, pois, perante o olhar de Musil, repleto de fina ironia, relativamente à estética, à literatura e à música alemãs da modernidade. No âmbito do romance, a personificação ficcionada das posições filosófico-estéticas nietzschianas (particularmente o ódio à música de Wagner e à cultura moderno-romântica decadente), concentra o núcleo das teorizações dedicadas à interpretação nietzschiana do pensamento musiliano presente em $O$ homem sem qualidades, permitindo, assim, ensaiar modos de apreciação do diálogo estético-cultural mantido por Musil com o pensamento de Nietzsche.

O carácter inflamado da paixão nietzschiana da personagem Clarisse constitui um elemento ficcional que se adensa na trama do romance. Desde logo, no início de O homem sem qualidades (obra que poderá ser lida, em última instância, como um palco onde desfilam e se apresentam personagens que dão corpo a ideias culturais, filosóficas, estéticas, etc...), Clarisse afigura-se como $a$ nietzschiana total e perfeita: ela é a possuidora das obras completas de Nietzsche, presente de casamento com Walter oferecido por Ulrich; ela é a representação ficcionada - continua e contundentemente audível - das ideias estéticas de Nietzsche contra o decadente romantismo musical (à la Wagner) de Walter e da sua hesitante

3 Ver Taskiran, 2000.

178 | Cad. Nietzsche, Guarulhos/Porto Seguro, v.42, n.2, p. 175-199, maio/agosto, 2021. 
Algumas considerações sobre o lugar da filosofia nietzschiana em...

genialidade doentia; ela é a promotora, a dado momento da trama narrativa, do "Ano Nietzsche", apresentado à Ação Paralela como título que encabeçaria o alternativo evento de comemoração dos 70 anos do reinado do imperador Franz Joseph, e onde deveria ter lugar a simbólica decisão de absolvição do louco Moosbrugger, o assassino de jovens mulheres; ela é, ainda, a representação de uma existência equivocamente envolta em loucura e insanidade, supostamente tomadas como marcas existenciais da própria figura de Nietzsche, especialmente nos momentos do romance em que a personagem de Clarisse, nas suas visitas a um velho manicômio, procurando, uma vez mais, ser levada a visitar Moosbrugger, pensa no filósofo Nietzsche, também ele louco, também ele condenado a viver, enclausurado, num lugar semelhante - em partes postumamente publicadas do romance, é Clarisse, ela mesma, quem se encontra internada numa ala psiquiátrica de um hospital, encarnando, assim, a suposta loucura nietzschiana tão intensamente desejada pela personagem feminina.

Tal desenho de Clarisse por Musil - Clarisse como a hiperbolização acrítica e incontida do pensamento de Nietzsche - poderá ser lida, porventura, como (mais) uma expressão da ironia musiliana, que, no romance $O$ homem sem qualidades, parece não desejar comprometer-se filosoficamente com nenhuma das direções possíveis à época, seja estas passadas ou emergentes. Perante o exacerbadamente complexo retrato de Clarisse, delineado entre a morbidez e a caricatura das posturas da personagem, somos impelidos a interrogar: quão nietzschiano permanece Musil? E, no entanto, este tipo de interrogação, assim literalmente formulada, não nos parece a mais adequada...

\section{O lugar de Nietzsche - o lugar de ' $N$ ' - no âmbito da ouvre musiliana}

Se, em termos de matéria filosófica, o romance de estreia de Musil O jovem Torless (Die Verwirrungen des Zöglings Törleß) se apresenta delineado sob o signo de Kant, o romance $O$ homem sem 
Bento, S.

qualidades poderia ser concebido como desenvolvido sob o signo de Nietzsche. Em relação a O jovem Torless, a primeiro romance de Musil, o elemento perturbador parece advir da leitura do imperscrutável Kant e da sua enigmática Crítica da razão pura. A insondabilidade do pensamento kantiano traduz-se como um dos eixos filosóficos que se desdobra, de modo intenso, numa experiência vivencial e psicológica do protagonista Torless. O elemento filosófico em Musil anuncia-se, assim, na sua œuvre literária desde o início e, no âmbito da sua biografia, afirma-se no momento em que o jovem escritor completa a sua formação realizada em instituições militares de ensino: a saída de Musil de tais escolas, primeiramente em Eisenstadt e posteriormente em Mährisch-Weißkirchen, bem como a sua inscrição na Universidade em Brünn para estudar engenharia, permitiram, pois, a descoberta e o contacto com um universo cultural de teatros, museus, galerias de arte e, especialmente, livrarias, inteiramente desconhecido para o jovem Musil até então. A filosofia impõe-se, assim, como um novo interesse.

Com efeito, Kant surge como o primeiro sinal de tal inquietação musiliana, e não propriamente o filósofo da sua juventude, Nietzsche. Tal poderá soar-nos desconcertante - e conduzir-nos, novamente, à questão: qual o lugar da filosofia de Nietzsche no pensamento musiliano? Ensaiar uma possível resposta a tal interrogação deverá, assim cremos, incluir a rejeição de uma apreciação que reduza Nietzsche a uma irrelevante paixão de juventude de Musil - paixão essa que, progressivamente, se traduziria num alvo de caricatura intelectual por parte do maduro romancista de $O$ homem sem qualidades.

Sustentar que o romance-maior de Musil se encontra desenvolvido sob o signo de Nietzsche não poderá constituir uma afirmação supérflua. Não se trata, bem entendido, de enumerar as múltiplas referências ao filósofo que abundam ao longo do romance e de toda a obra musiliana. Não é uma questão de quantidade de menções ou de alusões, mais ou menos explícitas. Trata-se, sim, de procurar delinear uma perspetivação

180 | Cad. Nietzsche, Guarulhos/Porto Seguro, v.42, n.2, p. 175-199, maio/agosto, 2021. 
Algumas considerações sobre o lugar da filosofia nietzschiana em...

que situe o filósofo no quadro cultural que Musil desenvolve no seu romance, propondo, assim, apreciar a figura de Nietzsche como o contraponto (qual Dionísio versus Sócrates) de uma outra figura que concentra todo o repúdio intelectual, nunca suavizado, do escritor Robert Musil - a saber, a personagem de Arnheim, que é, ele mesmo, a máscara através da qual fala Goethe. Já compreenderemos.

A modernidade de Musil poderá ser, assim, perspetivada à luz deste confronto cultural entre Nietzsche e Goethe. O nietzschianismo cultural de Musil poderá ser concebido através da apreciação da sua postura de ódio, deliberadamente exposta, confirmada e reiterada a cada página do romance, relativamente a Goethe, personificado na figura de Arnheim ${ }^{4}$. Como se Nietzsche se apresentasse, em Musil, como o novo vulto cultural capaz de destronar a figura de Goethe, propondo um novo modo crítico de pensamento e de existência que procuraria rejeitar o goethiano. Não é Nietzsche, através de Clarisse, que constitui o alvo da feroz ironia de Musil, mas, sim, Goethe. Curiosamente, tal como elucida Emer Herity no seu ensaio "Robert Musil and Nietzsche" (1991), os nomes de Nietzsche e de Goethe constituem as referências mais repetidamente presentes ao longo de toda a œuuvre musiliana: as menções incessantes ao nome de Nietzsche - um nome tão ininterruptamente inscrito na obra do escritor austríaco, que, por sua vez, passara a designá-lo segundo a abreviatura ' $N$ ', especialmente nos seus diários, traduzindo um hábito que só poderá sugerir familiaridade - apenas são ultrapassadas, em número, pelas referências de Musil a Goethe ${ }^{5}$. Nietzsche e Goethe: eis os dois nomes

\footnotetext{
4 Importaria sublinhar que o presente artigo não trata da relação do pensamento de Nietzsche com Goethe - uma relação que se poderia caracterizar, sem exagero, como total admiração pela figura, pela obra e pela 'filosofia de vida', sendo Goethe concebido por Nietzsche, tal como elucida Adrian Del Caro em Nietzsche contra Nietzsche. Creativity and the Anti-Romantic (1989), como modelo do seu antirromantismo e como expressão perfeita da (a)moralidade aristocrática-, mas, sim, da leitura musiliana de uma certa forma de existência, proliferando num momento cultural anterior à Primeira Guerra Mundial, que tomaria como modelo a vida exemplar de Goethe. O elemento goethiano em Musil não deverá ser confundido nem tratado de modo análogo com a visão nietzschiana de Goethe.

5 Ver Herity, 1991.
}

Cad. Nietzsche, Guarulhos/Porto Seguro, v.42, n.2, p. 175-199, maio/agosto, 2021. | 181 
Bento, S.

que se afirmam como duas presenças que moldam e determinam a obra de Musil. Mas, antes de analisar a oposição Nietzsche vs. Goethe no contexto de $O$ homem sem qualidades, talvez seja pertinente recuar até à juventude de Musil e aí analisar a atribuição de um insuspeito epíteto que o escritor delineara para si mesmo.

\section{Monsieur le vivisecteur}

Monsieur le vivisecteur: eis a designação que o jovem Musil atribui a si próprio e à sua postura filosófica nos seus primeiros diários, encabeçados pelo fascinante título Nachtbücher (e não Tagebücher) - os noturnários, numa possível tradução portuguesa. O epíteto que Musil desenvolve para si próprio não poderia soar mais nietzschiano, como que confirmando a paixão pelo pensamento e pela figura de Nietzsche que marcara a juventude do escritor. Com efeito, a designação monsieur le vivisecteur poderia ser lida como uma exultante evocação de uma postura filosófica nietzschiana - a da vivissecção: Vivisektion am guten Menschen -, tal como apresentada em Além de bem e mal, segundo esclarece Elisabeth Albertsen no ensaio incontornável "Jugendsünden? Die literarischen Anfänge Musils" (1970) ${ }^{6}$.

Leiamos, assim, as páginas (incluídas no Heft 4) do noturnário de monsieur le vivisecteur (possivelmente escritas antes de 1900, logo após Musil ter completado 18 anos de idade, e que revelam uma prosa diarística profundamente delineada à luz do tom filosófico de Nietzsche):

Eu vivo nas regiões polares; quando assomo à janela, mais não vejo do que brancas superfícies tranquilas que servem de pedestal à noite. [...]

Hoje é a primeira vez que "perceciono" o meu quarto, esta horrível confusão de blasfêmias estilísticas, como um todo unitário, como uma soma de superfícies de cores organicamente vinculadas a esta noite gelada que me obriga a uma espécie de reclusão, também ela a mim vinculada, pois, ao observar, através da janela, sobre os telhados cobertos de neve, esta

6 Ver Altersen, 1970.

182 | Cad. Nietzsche, Guarulhos/Porto Seguro, v.42, n.2, p. 175-199, maio/agosto, 2021. 
noite centro-europeia de janeiro, sinto-me como um túmulo de gelo sob um abóboda polar que reflete o olho interior. Uma espécie de panteísmo baseado em conhecimento fisiológico! Proponho-me, assim, escrever o meu diário e, por razões de gratidão, designá-lo-ei de noturnário, e somente considerarei terminada esta tarefa quando nenhuma palavra do conjunto perturbe a bela harmonia nascida das minhas atuais perceções.

Noturnário! Amo a noite pois esta carece de enigmas; durante o dia, os nervos são sacudidos uma e outra vez, até à cegueira, mas é à noite que certos animais predadores lançam as garras aos nossos pescoços para que nos possam estrangular, é à noite que a atividade dos nervos recupera depois da lassidão do dia e se dobra para o interior, é à noite que alcançamos uma nova perceção sobre nós mesmos, como se, subitamente, nos encontrássemos num quarto escuro com uma vela diante de um espelho que, por sua vez, não havia, até então, recebido raio de luz algum, e que absorvendo-o agora avidamente, devolve, a cada um de nós, a imagem do seu próprio rosto.

Predadores lançam as garras aos nossos pescoços para nos poderem estrangular. Houve reis que ungiam panteras aos seus carros e cujo máximo prazer consistia, porventura, na vaga possibilidade de serem despedaçados.

Acabo de encontrar um belíssimo nome para mim: monsieur le vivisecteur.

$\mathrm{Na}$ verdade, este ato de inventar um nome tão sonante para si próprio não revela ser mais do que pura afetação, pois não é necessário, salvo em algumas ocasiões de profunda prostração, de mal-estar por excesso de cansaço, recorrer a ele, encontrando, assim, numa única palavra, esses estímulos fundamentais que costumam proporcionar-nos força, esperança e entusiasmo. Não há que sentir vergonha.

Monsieur le vivisecteur: eu!

A minha vida: as aventuras e odisseias de um vivisecteur espiritual no início do século XX!

Que significa m.l.v.? Talvez o protótipo do futuro homem cerebral? Será? Mas as palavras possuem tantos matizes secundários, tantos sentidos duplos, evocam tantas sensações secundárias e tantas sensações duplas que faríamos bem em mantermo-nos afastados delas. (Musil, 1976, Vol. I, p.2).

$\mathrm{E}$, mais adiante, Musil, aquele que habita regiões polares, o grande vivisecteur espiritual do novo século, apresenta a tarefa filosófica do monsieur le vivisecteur: 
Bento, S.

No meu caso, trata-se do prazer de estar só comigo mesmo, completamente só. Da oportunidade de folhear a história, não propriamente destituída de interesse, do m.l.v., de entristecer-me neste momento e de voltar a sentir alegria no instante seguinte, de transformar-me no meu próprio historiador ou num ser científico que coloca o seu organismo sob o microscópio, contentando-se quando descobre coisas novas.

$\mathrm{E}$ isto, excecionalmente, não comporta qualquer afetação! [Estou na companhia de mim mesmo.] (Musil, 1976, Vol.I, p.3).

O leitor filosoficamente mais avisado tomará estas linhas musilianas como uma repercussão da paixão nietzschiana, perspetivando o jovem Musil como um discípulo atento do mestre, disposto a fazer cumprir a ordenação da filosofia de Nietzsche: a vivissecção, tarefa filosófica-psicológica dos pensadores do futuro, e cujo alvo, assim apresenta Nietzsche, deverá ser os ditos homens bons, os homo bonae voluntatis. Leiamos Nietzsche em Além do bem e do mal:

Os psicólogos franceses - onde é que ainda hoje há psicólogos senão em França? - não pararam de gozar o seu divertimento amargo e variado com a bêtise bourgeoise, como se... Enfim, denunciam alguma com isso, Flaubert, por exemplo, o bravo burguês de Ruão, por fim, não viu, não ouviu, nem provou mais nada; foi o seu gênero de autotortura e sutil crueldade. Como isto se tornou aborrecido, recomendo outra coisa, para variar, como divertimento: a astúcia inconsciente com a qual todos os bons, fortes e bravos espíritos medíocres se comportam em relação aos espíritos superiores e às suas tarefas, aquela astúcia retorcida e jesuítica que é mil vezes mais sutil do que o entendimento e o gosto desta classe média, nos seus melhores momentos - melhor até do que o entendimento da sua vítima; tudo isto é a comprovação repetida de que o "instinto" é o mais inteligente de todos os tipos de inteligência que foram descobertos até ao presente. Em resumo, estudai, vós, psicólogos, a filosofia da "regra" em luta com a "exceção": tendes aí um espetáculo digno dos deuses e da maldade divina! Ou então - tarefa ainda mais atual - praticai a vivissecação dos 'homens bons', do homo bonae voluntatis... de vós mesmos! (JGB/BM 218, KSA p.153). 


\section{A vivisseção como tarefa filosófico-psicológica presente em $\boldsymbol{O}$ homem sem qualidades ou o nietzschianismo da maturidade de Musil}

Será a filosofia de Ernst Mach ${ }^{7}$ a verdadeira e confirmada fonte de conhecimento e de prática literária para Musil, tal como sustenta Bouveresse? O estudioso francês não negaria (e como poderia fazêlo?!) a influência da filosofia ou da psicologia nietzschianas em Musil, mas não hesitaria em situá-la num momento determinado da vida e da obra do escritor, isto é, no âmbito da sua juventude ${ }^{8}$. Deste modo, o romance $O$ homem sem qualidades, iniciado na década de 1920 e que exigiria a intensa e laboriosa atenção de Musil até ao final dos seus dias, apresentar-se-ia como uma suposta expressão de maturidade do escritor, no interior do qual a figura de Nietzsche constituir-se-ia como um mero elemento caricatural, patente no desenvolvimento da personagem Clarisse e a das suas tão exultantes quão mórbidas evocações do filósofo. Musil enquanto monsieur le vivisecteur afigurar-se-ia, neste sentido, como uma anódina elucubração juvenil, destituída de consistência intelectual e de efetiva manifestação no âmbito da obra madura do escritor. E, todavia, como perspetivar - sem Nietzsche - a análise psicológica, perpassada de ironia sardônica, que se encontra desenvolvida em $O$ homem sem qualidades? Deveremos, de modo perentório, abandonar a possibilidade de apreciar, no romance musiliano, a realização da tarefa psicológica nietzschiana de vivissecção? Ou, num sentido

\footnotetext{
7 Com efeito, a filosofia de Ernst Mach constituíra o objeto da tese de doutoramento de Musil em Filosofia (finalizada em 1908) pela Universidade de Berlim, sob orientação de Carl Stumpf. Na sua tese de doutoramento, Musil refutaria o fenomenologismo - o inevitável idealismo, em última instância - do empirocriticismo de Mach. Sobre a influência da filosofia de Ernst Mach na obra de Musil, importaria ler o esclarecedor livro de Tim Mehigan Robert Musil and the Question of Science, Ethics, Aesthetics and the Problem of Two Cultures (2020), especialmente o capítulo intitulado "Musil, Ernst Mach and the Problem of Causality".

8 Florence Vatan, no seu livro Robert Musil et la question anthropologique (2000), segue a perspetivação do seu professor Jacques Bouveresse relativamente à redução da influência de Nietzsche à juventude de Musil.
} 
Bento, S.

oposto, não se afigurará pertinente conceber Musil como um dos grandes psicólogos - insuspeitamente próximo dos franceses, Flaubert e Stendhal, tão amados por Nietzsche - do novo século moderno, o século XX? Talvez esta via de compreensão se apresente mais promissora e interessante do que seguir as posições de Bouveresse ${ }^{9}$... Para compreendermos o nietzschianismo de maturidade de Musil, importaria retomar a oposição, já aqui enunciada, entre Nietzsche e Goethe no âmbito de $O$ homem sem qualidades. Com efeito, o lugar de Nietzsche no romance musiliano talvez não deva ser prontamente lido e interpretado segundo o desenho da personagem Clarisse; talvez um olhar mais fino e sutil se afigure indispensável para perspetivar o papel do pensamento de Nietzsche em $O$ homem sem qualidades. Cumpriria, pois, ponderar a possibilidade de o lugar de Nietzsche no romance em causa não consistir na representação, mais ou menos caricatural, de um conjunto de posições filosóficas confusa e acriticamente expostas mediante a elaboração de uma personagemideia. A este respeito, parecer-nos-ia mais relevante atentar sobre a possibilidade de o nietzschianismo desta obra musiliana se apresentar latentemente inscrito no âmbito da tarefa psicológica de vivissecção desenvolvida pelo próprio romancista, tarefa essa que, utilizando a expressão de Robert B. Pippin no seu livro originalmente publicado em francês Nietzsche, moraliste français: la conception nietzschéenne

9 Distintamente de Bouveresse, Hans-Joachim Pieper propõe-se analisar a influência de Mach sem descurar a importância do pensamento de Nietzsche no âmbito da maturidade de Musil; neste sentido, e segundo os trabalhos de Pieper (Musils Philosophie. Essayismus und Dichtung im Spannungsfeld der Theorien Nietzsches und Machs; "Die Philosophie Robert Musils im Spannungsfeld der Theorien Nietzsches und Machs"), a relevância de ambos os pensadores, Mach e Nietzsche, constitui um eixo determinante da arte literária musiliana. Não obstante, as conclusões de Pieper concentram-se no tratamento das questões nietzschianas dos (assim designados) relativismo e perspetivismo que, segundo o comentador, perpassam o romance $O$ homem sem qualidades e moldam a personagem Ulrich. A apreciação atenta do romance de maturidade de Musil como expressão da tarefa filosófico-psicológica proclamada por Nietzsche - a sutil arte da vivisseção -, tal como presente na caracterização obsidiante da personagem Arnheim, não traduz, lamentavelmente, um elemento de consideração por parte de Pieper. Também Wolfgang Rzehak, no seu livro Musil und Nietzsche: Beziehungen der Erkenntnisperspektiven, procura seguir a leitura, que cremos constituir uma interpretação recorrente e esgotada, da análise do romance de Musil como repercussão literária do perspetivismo epistemológico nietzschiano.

186 | Cad. Nietzsche, Guarulhos/Porto Seguro, v.42, n.2, p. 175-199, maio/agosto, 2021. 


\section{d'une psychologie philosophique (2006), se constitui como "filosofia primeira", ocupando o lugar preponderante da metafísica enquanto tal $^{10}$. Musil apresenta-se, assim, a nossos olhos, como o psicólogo do futuro convocado por Nietzsche - e o seu objeto-alvo não é diferente do proposto pelo mestre: trata-se, com efeito, do homem bom, do homo bonae voluntatis.}

100 mencionado estudo de Robert B. Pippin, Nietzsche, moraliste français: la conception nietzschéenne d'une psychologie philosophique (2006), traduzido para língua inglesa sob o título Nietzsche, Psychology and First Philosophy (2020), procura sustentar a centralidade do trabalho do psicólogo e da psicologia no âmbito do pensamento de Nietzsche, refutando, assim, a visão heideggeriana relativa ao filósofo como um metafísico na esteira da tradição filosófica, e cujo conceito metafísico preponderante seria o conceito de vontade de poder. De acordo com Pippin, a postura filosófica nietzschiana seria, em bom rigor, uma postura próxima da dos moralistas e dos psicólogos franceses, principalmente Montaigne, Pascal, La Rochefoucauld. Evocando, igualmente, Além do bem e do mal, Pippin apresenta a sua visão acerca do pendor fulcral da psicologia em Nietzsche, elevada a filosofia primeira, destronando, deste modo, a metafísica clássica. Leiamos a passagem de Nietzsche citada por Pippin a partir da tradução portuguesa de referência: "Até ao presente, toda a psicologia permaneceu agarrada a preconceitos e a receios morais e não se atreveu a penetrar nas profundezas. Concebê-la como morfologia e teoria do desenvolvimento da vontade de poder, tal como eu a concebo, foi coisa que nunca aflorou o pensamento de ninguém, desde que se possa reconhecer, no que foi escrito até agora, um sintoma do que até agora se silenciou. $O$ poder dos preconceitos morais está muito enraizado no mundo espiritual, aparentemente o mais impassível e o mais despido dos preconceitos - e, ao que parece, tais preconceitos exercem aí um efeito prejudicial, inibitório, ofuscante e deturpador. Uma psicofisiologia autêntica tem de combater, no coração do investigador, resistências inconscientes; ela tem o coração contra si. Já uma teoria sobre a interdependência dos impulsos 'bons' e 'maus' produz, como uma forma de imoralidade mais sutil, uma indigência e um fastio na consciência mais poderosa e resoluta e, mais ainda, uma doutrina que faz derivar os impulsos bons dos impulsos maus. É certo que quem toma os afetos do gênero do ódio, da inveja, da avidez e da dominação, como afetos que condicionam a vida, como algo que, no governo geral da vida, deve estar fundamental e essencialmente presente e que, em consequência, deve ser ainda intensificado no caso de se desejar intensificar a vida, padece, numa tal orientação dos seus juízos, como que de um enjoo. E, todavia, esta hipótese não é, nem de longe, a mais desagradável e estranha, neste inaudito e quase novo domínio de conhecimentos perigosos: e há, de fato, centenas de bons motivos para que qualquer pessoa permaneça afastada dela - se puder! De outra forma, se o nosso barco perdeu o seu rumo, pois bem, apertem-se os dentes com força! Abram-se os olhos! As mãos agarrem-se ao leme! Afastamo-nos a toda a velocidade da moral, esmagamos e, talvez, com isso, trituramos os nossos próprios restos de moralidade, na medida em que fazemos e arriscamos a nossa viagem numa tal direção. Mas que importância temos nós? Jamais viajantes e aventureiros temerários abriram um mundo mais vasto de perspectivas: e o psicólogo que se sacrifica deste modo - não se trata do sacrifizio dell'intelecto, pelo contrário - poderá, pelo menos, exigir uma troca, que a psicologia seja novamente reconhecida como a rainha das ciências, para cujo serviço e preparação existem as restantes ciências. Pois, a partir de agora, a psicologia é novamente o caminho que conduz aos problemas fundamentais." JGB/BM, 23, KSA 5.166. 
Bento, S.

Voltemos à oposição Nietzsche vs. Goethe, agora de um modo mais demorado. $\mathrm{O}$ que significa o elemento goethiano em Musil? A sua expressão ficcionada é, pois, Arnheim, o representante da burguesia alemã espiritualizada, que segue o tipo de vida exemplar de Goethe. Como compreender a psicologia de Arnheim, o tipo goethiano? Com efeito, importaria ter presente que a figura de Arnheim - que, para vários estudiosos musilianos, ora se inspira em Walther Rathenau ora, inclusivamente, em Thomas Mann, o escritor-némesis de Musil - se assume como um "homem de grande formato" (Musil, 2008, Vol.1, p.266), como a expressão de um homem que conhece e se movimenta no "mistério do todo" (Musil, 2008, Vol.1, p.266), exemplarmente capaz de desenvolver as suas potencialidades de conhecimento no âmbito de todos os domínios do saber (a filosofia e o desporto, a arte e a economia, a ciência e a política, etc.) sem descurar a sua atividade de homem de negócios. Nele, o diletante, o mecenas, o erudito e o homem de pensamento combinam-se de modo excelente, tal como a sua dimensão de homem de saber, inspirado na eminente tradição da ânsia pela totalidade do ser e da verdade, se alia, sem quaisquer impedimentos, à sua dimensão de grande industrial e de homem de ação empreendedora e comprometido com a realidade do seu tempo. Estamos, pois, perante um homem total, universal. A "fusão de interesses alma-negócio" (Musil, 2008, Vol.1, p.504.) determina a exemplaridade do seu caráter - e o modo como cita ininterruptamente Goethe, a cada gesto ou a cada movimento seu, reitera a excecionalidade do seu ser.

A sua actividade estendia-se por vários continentes terrestres e outros tantos do saber. [...]

Uma tal amplitude de atuação e receptividade raramente são acompanhadas por realizações pessoais; mas também nisto Arnheim era uma exceção. Uma ou duas vezes por ano retirava-se para a sua propriedade para pôr no papel as experiências da sua vida intelectual. Esses livros e estudos, cuja lista já era imponente, eram muito procurados, alcançavam grandes tiragens e eram traduzidos em muitas línguas. Ninguém confia num médico 
doente; mas aquilo que é dito por alguém que tão bem soube cuidar da sua vida deve ter um bom fundo de verdade. Esta era a primeira fonte da sua celebridade (Musil, 2008, Vol.1, p.266).

\section{Continuamente:}

A segunda resultava da essência da ciência. A ciência goza entre nós de grande prestígio, e com razão. Mas, se é verdade que a investigação do funcionamento dos rins pode ocupar toda uma vida, não é menos verdade que há momentos - chamemos-lhes momentos humanistas - em que precisamos de chamar a atenção para a relação dos rins com a totalidade do povo. É por isso que Goethe é tão citado na Alemanha. Mas se um universitário fizer questão de mostrar que não possui apenas erudição, mas é também um espírito vivo e voltado para o futuro, a melhor maneira de o provar é citar obras cujo conhecimento não só honra quem o faz como também promete ainda mais honra, como uma ação em alta na Bolsa; nestes casos, as citações dos livros de Arnheim desfrutavam de crescente popularidade. As incursões que fazia nos mais diversos domínios da ciência para apoiar as suas ideias gerais nem sempre correspondiam, é certo, às mais rigorosas exigências. Mostravam sem dúvida um grande aparato de leituras, mas o especialista encontrava inevitavelmente pequenas inexatidões e equívocos pelos quais se reconhece um trabalho de diletante, tal como pelas costuras se distingue um vestido feito por uma costureira amadora de outro proveniente de um atelier a sério. Mas não se pense que os especialistas admiravam menos Arnheim por isso. Sorriam complacentemente, mas ele impressionava-os como um fenômeno dos tempos modernos, um homem de quem todos os jornais falavam, um rei da economia cujas realizações eram extraordinárias quando comparadas com as obras dos antigo reis; embora se permitissem observar que, nos respectivos domínios, tinham algumas coisas mais a dizer, mostravam-se reconhecidos, apelidando-o de brilhante, homem genial ou simplesmente universal, coisa que, entre especialistas, equivale a dizer que, entre homens, que uma mulher é um beleza à medida do gosto feminino. (Musil, 2008, Vol. I, p.266-267).

\section{O humanista Arnheim, formado na "melhor tradição de Frankfurt e de Goethe" (Musil, 2008, Vol. I, p.512), anuncia-se, perante olhares tão desconfiados quão venerandos, como a presença prussiana no}


Bento, S.

centro da Ação Paralela vienense, enamorando-se de uma "bela alma", senhora casada e de meia-idade, promotora das iniciativas espirituais que a elite do Império deveria desenvolver tendo em vista a comemoração dos 70 anos de reinado de Franz Joseph - Diotima, tal como sardonicamente denominada por Ulrich. A dedicação aos seus negócios e às suas atividades econômicas - que Ulrich tanto deprecia e que lhe merecem o mais contundente dos repúdios - acaba por perturbar o futuro amoroso de Arnheim ("um coração que vai a caminho dos cinquenta é um músculo endurecido" (Musil, 2008, Vol. I, p.506)) com Diotima. Em verdade, uma outra fonte de fama ou celebridade de Arnheim encontrava-se, justamente, no domínio da economia, apresentando-se, assim, o prussiano como expressão da implacável burguesia industrial - e não menos espiritualizada. Em Arnheim, o comerciante assertivo e resoluto (que o seu pai já era) reconcilia-se com o homem de pensamento, culto e visionário, segundo a firme convicção de que "o homem de pensamento tem de ser também um homem de ação” (Musil, 2008, Vol. I, p.505).

[...] sorriam quando ouviam falar das exigências filosóficas que o delfim pretendia impor aos da sua classe, ou introduzia mesmo nas negociações mais terra-a-terra. Tinha fama de citar poetas nas reuniões dos conselhos de administração, de insistir em que a economia não se podia separar das outras atividades humanas e que só se podia falar de negócios no contexto maior da vida nacional, intelectual e mesmo íntima. [...] Mas este é o caminho que conduz os negócios até à filosofia, porque hoje em dia apenas os criminosos se atrevem a prejudicar os outros sem filosofia; e assim se acostumaram a ver em Arnheim júnior uma espécie de legado papal para os seus negócios. Apesar de toda a ironia com que o brindavam, não lhes desagradava a ideia de poderem contar com ele como um homem que era tão capaz de defender os seus interesses num conclave de bispos como um congresso de sociólogos. [...] E agora só falta imaginarmos o efeito da filosofia de Maeterlinck ou de Bergson aplicado a questões como o preço do carvão ou a políticas dos cartéis, para termos uma ideia da deprimente influência do jovem Arnheim em reuniões de industriais ou nos gabinetes dos diretores em Paris, S. Petersburgo ou na Cidade do Cabo quando ia

190 | Cad. Nietzsche, Guarulhos/Porto Seguro, v.42, n.2, p. 175-199, maio/agosto, 2021. 
Algumas considerações sobre o lugar da filosofia nietzschiana em...

na qualidade de enviado do pai e tinha de ser ouvido até ao fim. Os êxitos para os negócios eram tão significativos como misteriosos, e foi daqui que nasceu o boato da importância extraordinária e da mão feliz deste homem. (Musil, 2008, Vol. I, p.268-269).

E, assim, Arnheim, descobrindo a sua aptidão para se tornar um caráter exemplar, no seguimento do modelo de Goethe, toma consciência, em si mesmo, do mistério da totalidade:

A forma básica do seu êxito era a mesma em toda a parte; envolto no halo mágico da sua riqueza e na fama da sua importância, era obrigado a conviver sempre com pessoas que o superavam nos respectivos domínios; ele agradava-lhes como alguém que não é do ramo mas tem dele conhecimentos surpreendentes, e intimidava-os na medida em que reunia em si faculdades que lhe permitiam estabelecer ligações entre o seu mundo e outros mundos de que eles nada sabiam. Assim, tornou-se natural para ele ser visto por grupos especializados como uma totalidade, um homem completo. Por vezes sonhava com uma espécie de era weimariana ou florentina da indústria e do comércio, sob a égide de personalidades fortes capazes de incrementar o bem comum e de fazer convergir em si as grandes realizações da técnica, das ciências e das artes e de dirigi-las a partir de cima. E sentia em si essa capacidade. Tinha o talento de nunca ser superior em nenhum domínio específico e que precisasse de prova, mas, graças a um equilíbrio fluido e a cada momento renovável a partir de si próprio, conseguia alcançar a posição de topo em qualquer situação, o que, provavelmente, será a grande qualidade fundamental do homem político; mas Arnheim estava, para além disso, convencido de que se tratava de um profundo mistério. E chamava-lhe o "mistério da totalidade" (Musil, 2008, Vol. I, p.269-270).

"Como um magnífico cravo de jardim se parece com as pobres cravinas que crescem à beira dos caminhos" (Musil, 2008, Vol. I, p.512), assim se assemelha Arnheim à classe média culta, com as suas origens situadas em meados do século XVIII e que, até inícios do século seguinte, se constituíra como a eminente intelligentsia espiritual das gerações de Kant, de Schiller, de Goethe. Como perspetivar a emergência e as características definidoras de tal intelligentsia 
Bento, S.

cultural e espiritualizada, de que Arnheim se pretende anunciar como legítimo sucessor? A este respeito, permitamo-nos ser conduzidos pelas elucidações de Norbert Elias. As primeiras páginas do seu estudo O processo civilizatório (1939) são dedicadas à clarificação de uma singular antítese entre dois conceitos, cultura (Kultur) e civilização (Zivilisation). De modo a enfatizar as diferenças (porventura, oposições) conceptuais que envolvem Kultur e Zivilisation, Elias evoca Kant, especialmente uma passagem apresentada no ensaio Idee $z u$ einer allgemeinen Geschichte in weltbürgerlicher Absicht, de 1784 (Ideia para uma história universal numa perspectiva cosmopolita):

Parece ter sido Kant quem primeiro exprimiu uma determinada experiência e antítese da sua sociedade em conceitos análogos. "Somos", diz ele, em 1784, em Idee zu einer allgemeinen Geschichte in weltbürgerlicher Absicht, "cultivados em alto grau pela arte e pela ciência, somos civilizados até à exaustão, tendo em vista toda a espécie de delicadeza e de decoro social..." "A ideia de moralidade", continua, "é do domínio da cultura. Mas utilizar essa ideia de modo a desenvolver um amor da honra que é apenas conforme aos bons costumes e o decoro exterior, isso é simplesmente civilizar." (Elias, 2006, p.84-85).

Segundo a leitura de Elias, as observações formuladas por Kant representam uma admirável - porque inaugural - perspetivação das diferenças conceptuais entre Kultur e Zivilisation: em verdade, assim Elias elucida, a filosofia kantiana constitui tanto um epítome quanto um acme de tal conceito - eminentemente germânico - de Kultur, avaliado como o conceito oposto de Zivilisation. A antítese conceptual Kultur vs. Zivilisation é assim desenhada por Elias: o conceito de Zivilisation, um conceito de pendor profundamente francês na sua origem e desenvolvimento, diz respeito, numa palavra, ao conjunto de comportamentos, atitudes, posturas e formas de conduta social, traduzindo, neste sentido, uma afinidade conceptual com as noções de boa educação, cortesia, gentileza, delicadeza, decoro social - ser civilizado consiste em ser urbano, possuidor de boas e belas maneiras; 
Algumas considerações sobre o lugar da filosofia nietzschiana em...

de um modo distinto, a singularidade conceptual que envolve a noção germânica de Kultur reside na sua referência a toda uma esfera de realizações ou feitos humanos, de ordem intelectual, filosófica, artística, religiosa - trata-se, asseverar-se-ia, de um conceito que convoca, num primeiro plano, o domínio daquilo que se poderia designar como o puramente espiritual (das rein Geistige). A emergência da noção germânica - de Kultur e, correlativamente, o surgimento da oposição Kultur vs. Zivilisation, poderá ser analisada à luz da consideração da gênese e do desenvolvimento de uma vanguarda burguesa alemã, uma nova intelligentsia alemã de classe média, composta por indivíduos provindos de um estrato social excluído das atividades da esfera pública e destituído de qualquer influência política, e cuja legitimação da sua existência decorrera, essencialmente, das suas realizações intelectuais, artísticas, científicas. A elaboração do conceito de Kultur poderá ser considerado como a autoimagem, o elemento que permite a autoconsciência - das Selbstbewusstsein - desta camada de jovens intelectuais, representando um estrato social que se movimenta no âmbito do puramente espiritual, "isto é, no plano do livro, na ciência, na religião, na arte, na filosofia, no enriquecimento interior, na 'formação' (Bildung) do indivíduo, sobretudo através do livro, na personalidade" (Elias, 2006, p.107-108).

Não será supérfluo dedicar alguma atenção às duas contraposições - um contraste social e político, por um lado, e um conflito linguístico, por outro lado - que envolvem, com efeito, a antítese-chave entre Kultur vs. Zivilisation: em verdade, no contexto do século XVIII, o nascimento da vanguarda burguesa alemã - a jovem intelligentsia germânica, provinda dos estratos sociais de classe média, que pensa e escreve em língua alemã, desenvolvendo esta mesma língua como um eminente veículo de Kultur, justamente, de filosofia, literatura, poesia... - representa a possibilidade de emergência de novas posturas e visões estéticas, profundamente contrárias àquelas que predominam entre a classe aristocrática, 
Bento, S.

nobre e cortês, profundamente francófila, isto é, a classe designada como civilizada. Tal como esclarece Elias, a universidade constitui o locus da nova intelligentsia alemã, que fala, escreve e pensa em alemão; a corte, por seu turno, representa o lugar tradicional da antiga aristocracia germânica, a camada superior cortês, composta por homens e mulheres civilizados de acordo com os gostos, posturas e mundividências francófilos - e que se expressam, tal como acontecia até então com todas as camadas aristocráticas do continente europeu, através da língua francesa. Elias não poderia ser mais elucidativo, e os seus esclarecimentos satisfazem, com brilhantismo teórico, todas as nossas conceções acerca das posturas estéticas da jovem intelligentsia germânica que desenvolveu o projeto romântico:

Superficialidade, cerimonial, conversação dirigida à exterioridade, por um lado, e interioridade, profundidade de sentimentos, leitura, formação da personalidade individual, por outro - é a mesma oposição que Kant exprime na sua antítese, referida a uma situação social muito específica, entre o ser civilizado e o ser culto. (Elias, 2006, p.98-99).

Esta nova intelligentsia espiritualizada, provinda das camadas burguesas da sociedade germânica, constitui e ilustra, sob o nosso olhar contemporâneo, a mais eminente cultura alemã representada por Kant, Lessing, Schiller, Goethe, Herder, Hölderlin. Também Arnheim, o personagem musiliano, ancorando-se na afirmação de si próprio como representante de tal intelligentsia tão burguesa quão espiritualizada - em especial, do modelo de vida exemplar de Goethe -, partilha da convicção de que os homens de ação e de negócios, possuidores do poder e da civilidade burgueses, estavam predestinados a ocupar "o lugar das velhas forças do ser" (Musil, 2008, Vol.I, p.513). Neste sentido, munido de tal nobre aspiração, Arnheim "havia levado a cabo a fusão de interesses entre alma e negócio, criando o conceito englobante de comerciante-rei; e o sentimento do amor que em tempos o fizera sentir que, no fundo, 
tudo é uno, constituía agora o cerna da convicção de que a cultura e os interesses humanos formam um todo harmônico" (Musil, 2008, Vol.I, p.513). De acordo com tal formulação de pensamento, Arnheim delineia a sua existência como um grande poema - o grande poema da vida -, que integraria a aliança perfeita entre o homem de teorização filosófica (e, nos seus escritos, a palavra alma faz as suas aparições mais prementes) e o homem de finanças. A proclamação da elevação da ação - a ação quotidiana e inscrita na circunstância presente, comprometida com e conforme a realidade estabelecida das coisas - à categoria de determinação também ela espiritual constitui, pois, uma das aspirações mais marcantes da figura de Arnheim. A este propósito, o modelo de Goethe, sinônimo de existência exemplar e de conduta ativa e comprometida com a realidade presente, impõese a Arnheim - eis Arnheim como a máscara de Goethe (a seguinte passagem de $O$ homem sem qualidades, que alude ao episódio da expulsão de Fichte de Jena devido a uma acusação de ateísmo, é amplamente ilustrativa e esclarecedora dos sentimentos de Musil relativamente a Goethe):

Arnheim estava convencido de que é um sinal de grandeza não criticar demasiado o seu próprio tempo. O melhor cavaleiro, dispondo do melhor cavalo, se o contrariar terá mais dificuldades em passar o obstáculo do que um outro que se ajuste aos movimentos do seu rocim.

Um segundo exemplo: Goethe! Foi um gênio como dificilmente poderá haver outro, mas também filho de comerciantes alemães elevados à condição nobre. Arnheim via nele o primeiro grande-escritor que essa nação produziu, e tomava-o como exemplo em muitas coisas. Mas a sua história preferida era a daquele caso conhecido em que Goethe, apesar de simpatizar com ele, deixou cair o pobre Johann Gottlieb Fichte quando este, professor de filosofia em Iena, foi chamado à ordem por ter falado, "com grandeza, mas talvez de maneira um tanto imprópria", sobre Deus e as coisas divinas; e porque, na sua defesa, assumiu um tom excessivamente "apaixonado", em vez de tentar safar-se "levando a coisa com mais moderação" como afirma o experiente mestre-poeta nas suas memórias. Arnheim não se teria limitado e comportar-se como Goethe, mas, tomando-o como referência, 
Bento, S.

teria tentado mostrar ao mundo que este era o modo goethiano de agir, e o único verdadeiramente significativo. Não se teria contentado com a verdade que diz que, estranhamente, temos mais simpatia por um grande homem que faz qualquer coisa de errado do que por um outro, menos grande, que se comporta corretamente; teria, isso sim, insistido em que a defesa intransigente das nossas próprias convicções não só é estéril como também desprovida de profundidade e ironia histórica; e quanto a esta última, teria dito que também ela é tipicamente goethiana, isto é, a ironia daquele que sabe adaptar-se às circunstâncias com um humor produtivo, e a quem a distância temporal acaba por dar razão. Se pensarmos que hoje, à distância de quase duas vidas humanas, a injustiça que se abateu sobre Fichte, o filósofo ousado, íntegro e um tanto exaltado, há muito tempo se tornou assunto privado que nada acrescenta à sua importância real, enquanto a importância de Goethe, apesar de ter procedido mal, em nada foi afetada pelo tempo, se assim pensarmos somos levados a concluir que a sabedoria do tempo de fato coincidia com a sabedoria de Arnheim (Musil, 2008, Vol. I, p. 569-570).

Com efeito, a tônica goethiana sobre a ação apresenta-se, em Arnheim, como a pedra de toque que diferenciava o seu caráter exemplar e a sua sabedoria de vida relativamente a Ulrich, o homem sem qualidades que tanto perturba o prussiano. Numa conversa com Solimão, Arnheim pensa em Ulrich:

- "Numa passagem do Wilhelm Meister, o grande Goethe apresenta com uma certa paixão um preceito para a vida correta". Diz ele: "Pensar para agir, agir para pensar!" Estás a entender? Não, é claro que não podes entender... - respondeu a si próprio, continuando calado. "É uma receita que contém toda a sabedoria de vida", pensou, "e aquele que quer ser meu adversário só conhece metade, o pensar!” (Musil, 2008, Vol. I, p.700).

$\mathrm{O}$ desprezo de Musil relativamente às gerações culturais alemãs dos séculos XVIII e XIX, especialmente no que concerne a Goethe, poderá ser lido à luz da curiosa análise de uma conferência, profundamente comovente, pronunciada pelo escritor em Berlim, datada de 16 de janeiro de 1927, a propósito do primeiro aniversário

196 | Cad. Nietzsche, Guarulhos/Porto Seguro, v.42, n.2, p. 175-199, maio/agosto, 2021. 
Algumas considerações sobre o lugar da filosofia nietzschiana em...

da morte de Rilke, com quem Musil se correspondia pontualmente. O longo texto que Musil dedica a Rilke ${ }^{11}$, tão elogiado por Alfred Kerr pelas suas virtudes críticas e ensaísticas que superariam o mero tom necrólogo, oferece, nas suas primeiríssimas páginas, a impressionante afirmação de que Rilke se apresenta como o maior poeta lírico alemão desde a Idade Média, um dos poucos capazes de elevar a poesia alemã à sua perfeição. Goethe, Schiller, Hölderlin... todos estes se afiguram superados pela figura e pela poesia de Rilke, aos olhos de Musil.

A modernidade musiliana poderá estar aqui inscrita: não se tratará, somente, de perspetivar a œuvre literária de Musil como expressão do grande modernismo artístico, mas, sim, de ponderar e apreciar a postura do escritor austríaco como manifestação de um novo modo de pensamento que inclui a possibilidade crítica, a da crítica cultural que resulta ser, também ela, psicológica - e, neste sentido, talvez o projeto filosófico musiliano se constitua como uma reverberação de uma postura (certamente) definida na sua juventude e nunca abandonada, a da psicologia nietzschiana da vivissecção, tal como o filósofo a pronunciara em Além do bem e do mal. Eis o nietzschianismo de maturidade de Musil: o romancista desdobra-se, ele mesmo, num psicólogo do futuro.

11 Ver Musil, 1978, Vol. II, p.1229-1242. 
Bento, S.

\title{
Some remarks on the place of Nietzsche's philosophy in Robert Musil's The man without qualities
}

\begin{abstract}
This paper proposes to develop an analysis of the influence of Nietzsche's philosophy in Robert Musil' oeuvre, especially in Der Mann ohne Eigenschaften. It is our purpose to consider the relevance of Nietzsche's philosophy in the mature Musil, and to refuse the conclusions advanced by Jacques Bouveresse regarding Nietzsche's philosophy as a mere (and infecund) philosophical influence limited to the youth Musil. Accordingly, the analysis of the importance of the vivisection, as a philosophical-psychological task proclaimed by Nietzsche (in Jenseits von Gut und Böse) in Musil's novel - Musil as a vivisecteur and psychologist - forms the heart of this article.
\end{abstract}

Keywords: Robert Musil, Nietzsche, vivisection, psychology

\section{Referências}

ALTERSEN, E. Jugendsünden? Die literarischen Anfänge Musils. In: Robert Musil. Studien zu seinem Werk. Herausgegeben von K. Dinklage, E. Albertsen, und Karl Corino. Hamburg: Reinbeck, 1970, p.9-25.

BOUVERESSE, J. La voix de l'âme et les chemins de l'esprit. Dix études sur Robert Musil. Paris: Seuil, 2001.

BOUVERESSE, J. Robert Musil. L'homme probable, le hasard, la moyenne et l'escargot de l'histoire. Paris: Éditions de l'éclat, 1993.

DEL CARO, A. Nietzsche contra Nietzsche. Creativity and the Anti-Romantic. Baton Rouge/London: Louisiana State University Press, 1989.

ELIAS, N. O Processo Civilizacional. Trad. Lídia Campos Rodrigues. Lisboa: Dom Quixote, 2006.

HERITY, E. Robert Musil and Nietzsche. In: Modern Language Review, Vol.86, No.4, October 1991, p.911-923.

MEHIGAN, T. Robert Musil and the Question of Science, Ethics, Aesthetics and the Problem of Two Cultures. Rochester/New York: Camden House, 2020.

198 | Cad. Nietzsche, Guarulhos/Porto Seguro, v.42, n.2, p. 175-199, maio/agosto, 2021. 
Algumas considerações sobre o lugar da filosofia nietzschiana em...

MUSIL, R. O Homem Sem Qualidades. Trad. João Barrento, 3 Vols. Lisboa: Dom Quixote, 2008-2009.

MUSIL, R. Rede zur Rilke-Feier in Berlin am 16. Januar 1927. In Gesalmmelte Weke in neun Bänden, herausgegeben von Adolf Frisé. Hamburg: Reinbeck, 1978, Vol.II, p.1229-1242.

MUSIL, R. Tagebücher, herausgegeben von Adolf Frisé, 2 Vols. Hamburg: Reinbeck, 1976.

NIETZSCHE, F. Para Além do Bem e do Mal, Obras Escolhidas de Friedrich Nietzsche, Vol.5. Trad. e notas Carlos Morujão. Pref. António Marques, Lisboa: Relógio d'Água, 1999.

NIETZSCHE, F. Sämtliche Werke. Kritische Studienausgabe in 15 Bänden. Herausgegeben von Colli und Montinari. Berlin/ München: Walter de Gruyter/ DTV, 1988.

PIEPER, H.-J. Die Philosophie Robert Musils im Spannungsfeld der Theorien Nietzsches und Machs. In: Nietzsche-Studien, Vol.3, N.1, 2001, p.267-294.

PIEPER, H.-J. Musils Philosophie. Essayismus und Dichtung im Spannungsfeld der Theorien Nietzsches und Machs. Würzburg: Königshausen u. Neumann, 2002.

PIPPIN, R. B. Nietzsche, moraliste français: la conception nietzschéenne d'une psychologie philosophique, Paris: Odile Jacob, 2006.

TASKIRAN, N. Wahnsinn hat Methode. Zur Clarisse-Figur und weiteren NietzscheSpuren in Musil's "Mann ohne Eigenschaften". München: GRIN Verlag, 2000. Disponível em: https://www.grin.com/document/33021

VATAN, F. Robert Musil et la question anthropologique. Préf. Jacques Bouveresse. Paris: P.U.F., 2000.

Enviado: 30/03/2021

Aceito: 21/04/2021 